\title{
Gestão Eficiente de Bacias Hidrográficas no Brasil: Dificuldades e Perspectivas de Soluções
}

\author{
Efficient management of watersheds in Brazil: \\ difficulties and perspectives of solutions
}

\author{
Marcos Callisto ${ }^{1 *}$, Diego Castro², Letícia de Morais², Frederic Mendes Hughes², \\ Andrei Kimura², Rodrigo Alves², Valéria Freitas², Laura Gagliardi², \\ Leandro Carmo Guimarães², Monica Andrea Gutierrez², Raphael Ligeiro², \\ Roberta Ferreira Miranda ${ }^{2}$, Fernando Resende ${ }^{2} \&$ Suellen Cristina Moreira de Sales ${ }^{2}$
}

\author{
${ }^{1}$ Departamento de Biologia Geral, Instituto de Ciências Biológicas - ICB, \\ Universidade Federal de Minas Gerais - UFMG, Belo Horizonte, MG, Brasil \\ 2 Programa de Pós-graduação em Ecologia, Conservação e Manejo da Vida Silvestre - ECMVS, \\ Universidade Federal de Minas Gerais - UFMG, Belo Horizonte, MG, Brasil
}

Nas últimas décadas a preocupação com os indesejáveis resultados dos efeitos de atividades humanas sobre o meio ambiente aumentou consideravelmente. Toleram-se cada vez menos os problemas ambientais que interferem na qualidade de vida, especialmente a poluição dos corpos d'água, devido ao lançamento e acúmulo de efluentes industriais e esgotos domésticos sem tratamento. Os rios que banham metrópoles, a exemplo de São Paulo e Belo Horizonte, estão praticamente mortos: servem apenas como um canal por onde escoa todo o esgoto produzido pelas atividades cotidianas dos indivíduos da população urbana.

O estabelecimento da Política Nacional de Recursos Hídricos, instituída pela lei no 9.433 de 8 de janeiro de 1997, é um marco institucional no país. Incorpora princípios e normas para a gestão de recursos hídricos adotando as bacias hidrográficas como regiões naturais de abrangência e como unidade de gestão e planejamento. A água destas bacias é considerada um bem destinado ao consumo humano, de uso múltiplo e de domínio público, além de ser um recurso natural limitado e dotado de valor econômico (Tucci 2002).

Reconhece-la como recurso natural dotado de valor econômico é inevitável (Costanza et al. 1997) e a cobrança pelo seu uso econômico, começando pelos grandes usuários, visa incentivar que a utilização da água o seja de modo racional. De fato, é necessário garantir que os bens ambientais

\footnotetext{
${ }^{*}$ Send correspondence to: Marcos Callisto

Departamento de Biologia Geral,

Instituto de Ciências Biológicas - ICB,

Universidade Federal de Minas Gerais - UFMG,

CP 486, CEP 30161-970, Belo Horizonte, MG, Brasil

E-mail: mcallisto13@gmail.com
}

sejam valorizados monetariamente, em especial naquelas áreas sob a influência de empreendimentos potencialmente impactantes, porque nestes casos as reparações sociais ou ambientais não atendem satisfatoriamente a todos os interesses das populações humanas afetadas (Brasil 2005). É interessante registrar que a lei agrícola 8.171/1991, precedendo à lei 9433/97, no seu artigo 20 diz:

"As bacias hidrográficas constituem-se em unidades básicas de planejamento do uso, da conservação e da recuperação dos recursos naturais." (Brasil 1991)

No entanto, as leis brasileiras reconhecem a qualidade da água tendo em vista apenas o seu grau de potabilidade e balneabilidade não considerando a integridade ecológica dos ecossistemas aquáticos que constituem as bacias hidrográficas. Por isso, a classificação dos corpos d’água é realizada por meio do estabelecimento de padrões de qualidade determinados pela ocorrência de variáveis-críticas que afetam decisivamente essa qualidade (p. ex. quantidade de matéria orgânica como DBO ou DQO). Estas podem ser de origem antrópica (esgotos domésticos) ou natural (macrófitas aquáticas em decomposição). A utilização da bacia hidrográfica como unidade territorial, para a qual a gestão de recursos hídricos deve ser dirigida, deve-se a uma abordagem ambiental integrada, necessária para que se avalie adequadamente os impactos que podem ocorrer devido à implantação de empreendimentos que têm alto potencial impactante, tal qual a instalação de hidroelétricas. Esta abordagem integrada, realizada em fase anterior à concessão do licenciamento ambiental, leva em conta os efeitos cumulativos e sinérgicos que tais empreendimentos poderão causar sobre os recursos naturais e as populações 
humanas assentadas nas áreas sob influência das bacias (Tucci 2002).

A elaboração de documentos, normas e programas, tais como a Agenda 21 (CNUMAD 1992: 333), a lei 9.433/97 e o "Quadro de Diretrizes para as Águas" (WFD 2000/60/ EC) (European Commission 2003), é importante para a criação de mecanismos pelos quais a conservação dos recursos naturais possa ser efetivada. A implementação desses mecanismos deve ajudar a fortalecer o diálogo entre os múltiplos usuários de recursos hídricos, o meio acadêmico e populações humanas que vivem em bacias hidrográficas. O resultado dessa implementação seria a proposição de medidas preventivas que, se utilizadas pelos gestores ambientais e tomadores de decisões, resultariam na conservação destas bacias. Neste caso, assume-se que a participação direta das populações humanas seja indispensável para que uma gestão eficiente e realista das bacias hidrográficas seja uma realidade.

Individualmente ou por meio de associações, vários países trabalham no sentido de melhor avaliar o estado de integridade das assembléias de organismos que vivem em ecossistemas de água doce, a fim de implementar programas de biomonitoramento de bacias hidrográficas em escalas nacional e transnacional. Nos Estados Unidos, demandas por um biomonitoramento padronizado e unificado, oriundas do setor governamental, mobilizaram a Agência de Proteção Ambiental norte-americana (US-EPA) a elaborar protocolos amostrais padronizados e a implementar programas de biomonitoramento em larga escala. Por meio da execução do projeto Environmental Monitoring and Assessment Program (EMAP-West), de 2000 a 2004 foram amostrados 1.285 trechos de rio em 12 Estados do oeste norte-americano. Em 2004, o projeto Wadeable Streams Assessment utilizou dados obtidos por meio da avaliação de 1.536 trechos de rio em toda a América do Norte continental. O primeiro projeto serviu como piloto, pois em sua execução foram testadas metodologias e estratégias de biomonitoramento que utilizaram variáveis de hábitat, química da água, peixes, metais pesados acumulados em tecidos de peixes, macroinvertebrados bentônicos e perifíton como indicadores de integridade ambiental. Por intermédio do Wadeable Streams Assessment fez-se a primeira tentativa de realizar-se um biomonitoramento em escala nacional no continente norte-americano. Porém, neste caso, apenas variáveis de hábitats físicos, química da água e macroinvertebrados bentônicos foram os indicadores utilizados.

Na Austrália, país no qual os recursos hídricos são naturalmente escassos, implementou-se em 1994 um protocolo de biomonitoramento em escala nacional, Australian River Assessment System (AusRivAs), baseado no modelo inglês River In Vertebrate Prediction and Classification System (RIVPACS). O AusRivAs utiliza modelos preditivos por meio dos quais é possível comparar a estrutura das assembléias de macroinvertebrados bentônicos que ocorrem em trechos de rios submetidos a impactos ambientais à dos trechos considerados em "condição de referência", isto é, os locais minimamente impactados por intermédio de atividades antrópicas.

O "Quadro de Diretrizes para as Águas" (Water Framework Directive, EU 2000), a política de recursos hídricos da União Europeia (UE), estabelece que todos os países da UE devem realizar a avaliação dos seus cursos d'água utilizando "condição de referência", principalmente considerando as assembléias de espécies de peixes, algas e bentônicas. No Brasil, os comitês das bacias hidrográficas do Rio das Velhas e do Rio São Francisco têm discutido ativamente a implantação de Programas de Biomonitoramento a longo prazo, após a conclusão de seus Planos de Manejo. Estes Programas utilizarão as bases metodológicas padronizadas empregadas na América do Norte, Austrália e União Européia, adaptando-as, validando-as e as ajustando às características regionais brasileiras.

$\mathrm{Na}$ América do Norte a obrigatoriedade legal de adotar o referido monitoramento foi o ponto de partida para realizar estudos de ampla abrangência, que resultaram no conhecimento sobre as relações entre a biodiversidade e os serviços ecológicos prestados pelos ecossistemas aquáticos de água doce. De forma análoga, no Brasil é chegada a hora para que a legislação ambiental seja implementada e se estabeleça a necessidade de monitoramento biológico em larga escala. Obviamente para a realização destes monitoramentos devem ser adotadas metodologias padronizadas, pessoal bem treinado e custos financeiros garantidos, tal como ocorre nos países acima comentados.

\section{Bacias Hidrográficas e Desenvolvimento Sustentável}

O uso e ocupação do solo, ocasionados por meio da expansão urbana e atividades industriais e agrosilvopastoris, são as principais causas da crise ambiental contemporânea (Shun-Li et al. 2010), particularmente no que diz respeito à integridade dos ecossistemas de água doce. Integridade significa a magnitude em que um ecossistema ou comunidade biológica impactada desvia-se das condições originais. Ela pode ser ainda definida como a capacidade que o ecossistema tem em se auto-sustentar e deste modo manter uma comunidade de organismos balanceada, integrada e adaptada (Moulton 1998). As ações das atividades humanas resultam em uma situação de flagrante contradição: de um lado é necessário que o abastecimento, distribuição e geração de energia por meio do uso da água sejam resolvidos a fim de promover os desenvolvimentos econômico e social; de outro, tais intervenções, provocam um incremento considerável dos danos ambientais. A priorização das dimensões econômica e social, excluindo-se a dimensão ambiental como componente adicional importante, culminou na crise global da biodiversidade em ambientes aquáticos de água doce: 10.000 a 20.000 espécies de organismos foram extintas ou estão ameaçadas de extinção (Strayer \& Dudgeon 2010). Por este motivo, o equilíbrio entre as atividades que constituem o tripé da sustentabilidade, implementação de 
medidas conservacionistas, programas de manejo adaptativo e gestão integrada de bacias hidrográficas, torna-se uma demanda emergencial (Collischonn et al. 2001; Tucci 2002).

No Brasil vivemos uma crise de gestão dos recursos hídricos decorrente da utilização de práticas gerenciais inadequadas, pois estas se baseiam apenas no monitoramento realizado por intermédio da mensuração de parâmetros físicos, químicos e microbiológicos (Buss et al. 2003). Além disso, falta também no Brasil estabelecer uma política ambiental que funcione na prática, deficiência esta atribuída em parte à omissão dos líderes mundiais e à ausência de conscientização por parte expressiva da população mundial sobre a urgência e magnitude do problema (UNESCO 2003).

Adicionalmente, a gestão de bacias hidrográficas precisa atender ao planejamento governamental considerando o valor intrínseco da proteção, conservação e utilização sustentável de seus recursos naturais (Tundisi 2008), que devem prevalecer sobre os interesses particulares ou de determinados grupos políticos influentes. Para evitar que isso aconteça, é fundamental que grupos sociais, afetados pelas decisões dos Comitês de Bacias Hidrográficas e os demais usuários dos recursos hídricos, se mobilizem para que sejam realizadas audiências públicas. A mobilização social somada a iniciativas políticas e à conscientização da sociedade podem favorecer o desenvolvimento da legislação que fundamente em bases legais a implementação de Programas de Biomonitoramento (Bai et al. 2010).

Após uma década e meia da vigência da Política Nacional de Gerenciamento dos Recursos Hídricos e da determinação da constituição dos Comitês de Bacias Hidrográficas no Brasil, mudanças ocorreram no sentido de garantir a utilização da água doce por meio de uma gestão adequada e sustentável. A aplicação da outorga e cobrança pelo uso da água e a implementação dos planos de gestão das bacias hidrográficas são exemplos de instrumentos que a viabilizam. Integrando os referidos planos, o fortalecimento da gestão de bacias poderá ser efetivado por meio da manutenção de redes de monitoramento em tempo real. O monitoramento de avaliação da qualidade ambiental deve identificar e apontar locais sujeitos ou não a contaminação, poluição, erosão ou outros danos ambientais quaisquer (Nascimento \& Villaça 2008). Além disso, o monitoramento deve indicar sobre o que conservar e qual o custo associado. Dessa maneira, tais estudos ajudariam a definir estratégias de utilização, gestão, controle e conservação (Cottingham \& Carpenter 1998).

Apesar de ser previsto que instituições de fiscalização ambiental estaduais/municipais possam/devam realizar o monitoramento ambiental, para efetuá-lo há enorme carência de pessoal bem treinado. Para suprir essa carência, é importante celebrar convênios entre instituições públicas responsáveis pela gestão dos recursos hídricos e instituições de ensino e pesquisa. Tais convênios poderiam ser viabilizados economicamente por intermédio dos recursos financeiros provenientes da cobrança pelo uso da água bruta para fins econômicos, o que daria maior suporte à efetivação do Plano Nacional de Recursos Hídricos, a exemplo do que acontece nos estados de São Paulo e Minas Gerais (Matta-Machado 2008).

O estabelecimento de redes transdisciplinares, que facilitem a ocorrência de uma gestão participativa e efetiva otimização de esforços e recursos, é essencial para que os executores do monitoramento sejam bem treinados. Tal situação já ocorre em São Paulo (Tundisi, 2008), Estado pioneiro em criar um sistema integrado de implementação dos instrumentos para gestão dos recursos hídricos. Em Minas Gerais, a Deliberação Normativa Conjunta COPAM/CERH-MG 001 de 5 de maio de 2008, estabelece como meta ambiental a implementação de Programas de Biomonitoramento. Estes programas seriam implantados por meio do uso de indicadores biológicos, obtidos em áreas de referência (locais minimamente alterados por atividades humanas e que representem a qualidade ambiental e biodiversidade regional). Além disso, esta Deliberação prevê que os estudos deveriam focalizar preferencialmente as assembléias de espécies do perifiton, organismos patogênicos e os vetores de doenças, destacando-se os organismos bentônicos, peixes, macrófitas aquáticas e zooplâncton que vivem em ecossistemas lóticos. Estes organismos são reconhecidamente sensíveis a mudanças na qualidade da água e caracterizam-se por ótimos bioindicadores de saúde ambiental. Complementarmente Feio et al. (2010) comprovam que processos ecológicos como produção primária e decomposição de matéria orgânica são integradores de informação em bacias hidrográficas, podendo portanto serem integrados em Programas de Biomonitoramento de bacias hidrográficas.

Finalmente, somente com a participação popular haverá uma gestão de bacias hidrográficas eficiente. Para que isso ocorra, a população deve ser motivada a participar adotando-se atividades educativas que estimulem a percepção e a conscientização ambientais, especialmente nas escolas e comitês de bacias.

\section{Referências}

Bai X et al., 2010. Urban policy and governance in a global environment: complex system, scale mismatches and public participation. Current Opinion in Environmental Sustainability, 2:129-135. http://dx.doi.org/10.1016/j. cosust.2010.05.008

Brasil. 1991. Lei no 8.171, de 17 de janeiro de 1991. Dispõe sobre a política agrícola. Diário Oficial da República Federativa do Brasil, Brasília. (1991 jan.).

Brasil. Ministério do Meio Ambiente - MMA. 2005. Termo de referência do Estudo da Avaliação Ambiental Integrada dos aproveitamentos hidrelétricos da bacia do rio Tocantins. EPE Empresa de Pesquisa de Energética, Ministério das Minas e Energia.

Buss DF, Baptista DF \& Nessimian JL, 2003. Bases conceituais para a aplicação de biomonitoramento em programas de avaliação da qualidade da água de rios. Cadernos de Saúde Pública, 19:465-473. http://dx.doi.org/10.1590/ S0102-311X2003000200013 
Collischonn W, Tucci CEM \& Clarke RT, 2001. Further evidence of changes in the hydrological regime of the River Paraguay: part of a wider phenomenon of climate change? Journal of Hydrology, 245:218-238. http://dx.doi. org/10.1016/S0022-1694(01)00348-1

Conferência das Nações Unidas sobre Meio Ambiente e Desenvolvimento - CNUMAD, 1992. Agenda 21. Brasília: Senado Federal.

Costanza R et al., 1997. The Value of the World's Ecosystem Services and Natural Capital. Nature, 387:253-260. http:// dx.doi.org/10.1038/387253a0

Cottingham KL \& Carpenter SR, 1998. Population, community, and ecosystem variants as ecological indicators: phytoplankton responses to whole-lake enrichment. Ecological Applications, 8(2):508-530. http://dx.doi. org/10.1890/1051-0761(1998)008[0508:PCAEVA]2.0.CO;2

European Commission, 2003. Common implementation strategy for the Water Framework Directive (2000/60/ $E C)$. Working Group REFCON. Guidance document no. 10, Riversand lakes - Tipology, reference conditions and classification systems.

Feio MJ et al., 2010. Functional indicators of stream health: a river basin approach. Freshwater Biology, 55:1050-1065. http://dx.doi.org/10.1111/j.1365-2427.2009.02332.x
Matta-Machado ATG, 2008. A construção de um Programa de Revitalização na Bacia do Rio São Francisco. Estudos Avançados, 22:195-210.

Moulton TP, 1988. Saúde e integridade do ecossistema e o papel dos insetos aquáticos. In: Nessimian JL \& Carvalho AL (eds.). Ecologia de Insetos Aquáticos. Rio de Janeiro: PPGE-UFRJ. p. 281-298. (Série Oecologia Brasiliensis).

Nascimento, WM \& Villaça MG, 2008. Bacias hidrográficas: planejamento e gerenciamento. Revista Eletrônica da Associação dos Geógrafos Brasileiros- Seção Três Lagoas, 1(7):102-120.

Shu-Li H, Chia-Tsung Y \& Li-Fang C, 2010. The transition to an urbanizing world and the demand for natural resources. Current Opinion in Environmental Sustainability, 2:136-143. http://dx.doi.org/10.1016/j.cosust.2010.06.004

Strayer DL \& Dudgeon D, 2010. Freshwater biodiversity conservation: recent progress and future challenges. Journal of the North American Benthological Society, 29(1):344-35.

Tucci CEM, 2002. Gerenciamento da drenagem urbana. Revista Brasileira de Recursos Hídricos, 7(1):5-25.

Tundisi JG, 2008. Water resources in the future: problems and solutions. Estudos Avançados, 22:7-16. http://dx.doi. org/10.1590/S0103-40142008000200002

UNESCO, 2003. Water for people, water for life. UNESCO/ WWAP. Executive Summary of the UN World Water Development Report.

Recebido: Outubro 2011

Primeira Decisão: Novembro 2011

Aceito: Novembro 2011 